\title{
POLÍTICAS PÚBLICAS E DIREITO À SAÚDE: NECESSIDADE DE UMA ALTERNATIVA PARA ALÉM DA JUDICIALIZAÇÃO
}

\author{
Heloisa Sami Daou ${ }^{1}$ \\ Juliana Rodrigues Freitas ${ }^{2}$
}

RESUMO: o presente artigo pretende analisar políticas públicas como instrumentos para garantir os direitos fundamentais, especialmente o direito social fundamental à saúde. Buscase, inicialmente, a compreensão do conteúdo do direito à saúde diante da necessidade de uma interpretação ampliativa. Depois, analisa-se a relevância jurídica das políticas públicas para garantia desse direito no Brasil, com ênfase no Sistema Único de Saúde - SUS. A ineficácia dessas políticas gera uma crescente judicialização do direito à saúde, que não se mostra a solução mais adequada para concretização desse direito, impondo alternativas para além das demandas judiciais.

Palavras-Chave: Políticas Públicas; Direitos Fundamentais Sociais; direito à saúde; Sistema Único de Saúde; judicialização.

\section{PUBLIC POLICY AND THE RIGHT TO HEALTH: NEED FOR AN ALTERNATIVE BEYOND JUDICIALIZATION}

\begin{abstract}
:
The present article aims to analyze public policies as instruments to guarantee fundamental rights, especially the fundamental social right to health. It is initially sought to understand the content of the right to health in the face of the need for an expansive interpretation. Then, it is analyze the legal relevance of public policies to guarantee this right in Brazil, with emphasis on the Unified Health System - SUS. The ineffectiveness of these policies leads to a growing judicialization of the right to health, which does not prove to be the adequate solution to achieve this right, imposing alternatives beyond judicial demands.
\end{abstract}

Keywords: Public policy; Fundamental Social Rights; right to health; Unified Health System; Judicialization.

\section{INTRODUÇÃO}

O tema políticas públicas vem adquirindo crescente destaque desde o final do século passado e começo do presente século, assim como todos os aspectos que o envolvem, tais como as instituições e regras que regem o processo de elaboração, implementação e controle das políticas, como também os seus legítimos destinatários.

No Brasil, o tema possui considerável importância por muitos motivos, dentre os quais, pelo fato de que não basta a Constituição da República Federativa do Brasil (CRFB/88)

\footnotetext{
${ }^{1}$ Mestranda em Direito, Políticas Públicas e Direitos Humanos do Centro Universitário do Estado do Pará. Email: helo_daou@yahoo.com.br

${ }^{2}$ Mestre e Doutora em Direito pela Universidade Federal do Pará. Professora da Graduação e Mestrado do Centro Universitário do Pará - CESUPA. E-mail: rodriguesfreitasjuliana@ gmail.com
} 
prever uma enorme gama de direitos sociais sem que se compreenda como os poderes públicos e os órgãos do Estado devem atuar para efetivar, na prática, tais direitos.

Nesse sentido, de acordo com o modelo instituído no Brasil a partir de 1988, o Estado alça a posição de interventor no campo econômico e social, e não mais atua como mero expectador, apenas - tornando-se um dos sujeitos ativos do desenvolvimento e da justiça social, devendo garantir as necessidades básicas e essenciais ao ser humano, sem discriminação e em sua plena garantia de eficácia. Ou seja, toda ação do Estado deve estar direcionada para concretização dos seus fins característicos, sendo, esta, inclusive, a exigência dos fundamentos da República, especialmente para o exercício da cidadania e da dignidade da pessoa humana.

Por essa razão, deve-se compreender as políticas públicas como categorias normativas, com a função jurídica de realizar a intermediação dos anseios da sociedade diante do Estado e dos governos, buscando-se esquematizar os interesses de todos os seguimentos sociais e os interesses dos indivíduos para uma concreta realização de direitos.

Assim, é fundamental a existência de estruturadas e bem definidas políticas públicas, sob pena de que a Constituição se torne letra morta, sem qualquer eficácia prática: a concretização dos direitos sociais depende de políticas eficazes que devem ser pensadas e executadas pelo Estado, ao lado da sociedade organizada que tem, sobretudo, que controlar a realização dessas políticas.

Somado a isso, o direito à saúde está na CRFB/88 como um direito social fundamental, tendo o legislador, desde logo, determinado a sua importância e a forma de atuação do Estado para a sua garantia, que se dá por meio de políticas públicas, com a implantação do Sistema Único de Saúde - SUS em suas diversas formas de funcionamento.

Porém, os últimos anos foram marcados, e continuam sendo, por um aumento considerável de pessoas que acionam o Poder Judiciário para terem garantido o direito à saúde em demandas envolvendo, em sua maioria, tratamentos médicos e aquisição de medicamentos, pois não raro as políticas públicas demonstram ineficácia prática.

No presente artigo busca-se a compreensão do conceito do direito à saúde, bem como da forma que foi definida pelo legislador como mecanismo de garantia desse direito social que se dá por meio das políticas públicas; a partir da constatação de que, por vezes, tais medidas são ineficientes, o que acarreta a necessidade de atuação do judiciário, propõe-se uma análise para além, com objetivo de repensar a judicialização a partir da necessidade urgente de medidas que sejam anteriores a ela, podendo-se também usar a expressão medidas para além, ou superiores à judicialização no sentido de maior eficácia prática.

Para tanto, destacar-se-á, inicialmente, a necessidade de uma interpretação ampliativa do conceito de saúde que considere, por um lado, que a garantia desse direito pode exigir outras medidas sociais que melhorem a qualidade de vida das pessoas, vistas como um todo em seus determinados contextos de existência e, por outro lado, trata-se de um direito de fruição individual, não podendo o Estado desconsiderar que as pessoas vão manifestar necessidades distintas.

Depois, deseja-se tratar das políticas públicas e da relevância jurídica desse conceito, no sentido de que são instrumento para garantia do direito fundamental à saúde, com ênfase no Sistema Único de Saúde (SUS). Portanto, essas políticas devem ser fortalecidas, pois, ao contrário, cresce o número de demandas judiciais.

Assim, no presente artigo, não será discutida a possibilidade de judicialização, pois, acredita-se que o tema já foi suficientemente estudado, e considera-se legítimo o controle judicial de políticas públicas envolvendo direito à saúde. Mas, diante da atual realidade débil das políticas públicas de prestação desse direito social no Brasil e o consequente aumento de 


\title{
Políticas públicas e direito à saúde: necessidade de uma alternativa para além da judicialização
}

demandas judiciais, este breve texto tentará lançar alternativas anteriores à judicialização, ou mesmo posteriores, desde que reflitam positivamente na realidade prática.

Tendo em vista o objetivo do presente artigo, a metodologia utilizada foi a de revisão bibliográfica de livros, artigos científicos e periódicos pertinentes ao tema, e que pudessem permitir uma melhor compreensão do objeto deste ensaio.

\section{CONTEÚDO DO DIREITO FUNDAMENTAL À SAÚDE: NECESSIDADE DE UMA INTERPRETAÇÃO AMPLIATIVA}

Desde 1988, a dignidade da pessoa humana é um dos valores fundamentais da ordem jurídica brasileira, princípio-matriz de toda atuação estatal, elencada como fundamento do Estado Brasileiro ${ }^{3}$, razão pela qual se pode afirmar: "é o Estado que existe em função da pessoa humana, e não o contrário, já que o ser humano constitui a finalidade precípua, e não o meio da atividade estatal" (SARLET, 2012, p. 80).

Assim, o constituinte eleva o homem à condição de elemento central e impõe ao Estado o dever de garantir a mais variada gama de direitos e liberdades, tudo com vistas a garantir o bem estar do ser humano. Dias (2007, p. 116) afirma que "a dignidade da pessoa humana impõe-se como uma base estrutural sobre a qual os sistemas jurídicos modernos são construídos".

Ao lado da dignidade, também como fundamento da República Federativa do Brasil está a cidadania ${ }^{4}$, e sobre este aspecto, acrescenta Smanio (2013, p. 4):

\begin{abstract}
A cidadania, que ganhou uma nova visão constitucional em 1988, passando a ser fundamento do nosso Estado Democrático e Social de Direito, com amplos direitos assegurados na Constituição, precisa também ser efetivada em nossa vida social, deixando de ser apenas uma previsão formal do sistema jurídico.

Cidadania e Direitos Fundamentais passam a constituir um "Núcleo Duro" do chamado Estado Democrático e Social de Direito, trazendo as Políticas Públicas para o centro do debate político e jurídico.
\end{abstract}

Desse modo, os fundamentos da dignidade da pessoa humana e da cidadania dão unidade de sentido à realização dos direitos sociais fundamentais e impõem ao Estado o dever de sua garantia em toda e qualquer atuação. Isso, por dois motivos: primeiro porque na garantia de direitos fundamentais vê-se garantida a dignidade, atributo de todos os seres humanos que os torna merecedor de um mínimo indispensável para viver bem.

Depois, porque quando a Constituição da República estabelece a cidadania como princípio fundamental ela “(...) abrange essa dimensão de concretização dos direitos fundamentais. Daí falarmos que as Políticas Públicas se legitimam na concretização da cidadania" (SMANIO, 2013, p. 13).

\footnotetext{
${ }^{3}$ Artigo $1^{\circ}$ da CRFB/88 - A República Federativa do Brasil, formada pela união indissolúvel dos Estados e Municípios e do Distrito Federal, constitui-se em Estado Democrático de Direito e tem como fundamentos: (...); III - a dignidade da pessoa humana; (...) (BRASIL, 1988, não paginado).

${ }^{4}$ Artigo $1^{\circ}$ da CRFB/88 - A República Federativa do Brasil, formada pela união indissolúvel dos Estados e Municípios e do Distrito Federal, constitui-se em Estado Democrático de Direito e tem como fundamentos: (...); II - a cidadania; (...) (BRASIL, 1988, não paginado).
} 
Nesse sentido, a própria Constituição já elenca a forma de atuação estatal, por meio de políticas públicas para garantias de direitos fundamentais sociais. Concretamente, cabe ao Estado a promoção da dignidade e cidadania assegurando prestações materiais que possibilitem um maior número de liberdades para que os seres humanos desenvolvam seu projeto racional de vida e sua personalidade. O resultado é a realização e eficácia do texto constitucional, deixando seu caráter meramente retórico.

Pensa-se, desse modo, no mesmo sentido de Brito Filho (2008, p.06), quando afirma:

Inicio dizendo que, quando penso no Estado, penso em um ente que é constituído não apenas para materializar a organização política definida por um povo, em determinado território, o que corresponde a uma visão clássica desse ente. Penso também em um ente que não é um fim em si mesmo, que não atua como algo que só existe para seus interesses e de seus governantes. Penso, sim, em um ente que existe, pela vontade da coletividade, para oferecer serviços (direitos) que foram definidos como essenciais, ou seja, para garantir e concretizar Direitos Fundamentais dentro de um determinado espaço. (...) Essa idéia não rejeita a estrutura existente, rejeita sua atuação se não ocorrer em prol dos interesses da coletividade.

Os direitos sociais fundamentais estão dispostos na CRFB/88 no art. $6^{05}$ e, ao reconhecer a estes direitos uma dimensão fundamental, o Estado obrigou-se a prestações positivas que os garantam a todos na integralidade. Ou seja, o constituinte tem os direitos fundamentais como baliza para atuação do Estado, basta observar a localização do dispositivo legal, logo no início do texto constitucional, para compreender que o constituinte quis desenvolver toda organização da República Federativa do Brasil a partir desse mínimo que deve ser garantido aos indivíduos.

Por isso, Sarlet (2015, pg. 67) afirma que os direitos fundamentais são "parâmetros hermenêuticos e valores superiores a toda a ordem constitucional e jurídica”. E, acrescenta:

Direitos fundamentais são, portanto, todas aquelas posições jurídicas concernentes às pessoas, que, do ponto de vista do direito constitucional positivo, foram, por seu conteúdo e importância (fundamentalidade em sentido material), integradas ao texto da Constituição e, portanto, retiradas da esfera da disponibilidade dos poderes constituídos (fundamentalidade formal), bem como as que, por seu conteúdo e significado, possam lhes ser equiparados, agregando-se à Constituição material, tendo, ou não, assento na Constituição formal (aqui considerada a abertura material do Catálogo) (SARLET, 2015, p. 78)

Os direitos fundamentais são, portanto, uma garantia de vida melhor que foi concedida pelo constituinte a todos os seres humanos. Eles são posições jurídicas essenciais a todas as pessoas, porque decorrentes, de uma forma ou de outra, da sua dignidade.

Desse modo, os direitos sociais fundamentais possuem uma tríplice característica: o Estado está obrigado a proporcioná-los aos indivíduos, ou a todos eles; eles são um mínimo indispensável, sem eles não há condições de vida digna e, ainda, eles são direitos essenciais para todas as pessoas. "Os direitos sociais encontram seu fundamento e sua função na

\footnotetext{
${ }^{5}$ Artigo $6^{\circ}$ da CRFB/88 - São direitos sociais a educação, a saúde, a alimentação, o trabalho, a moradia, o lazer, a segurança, a previdência social, a proteção à maternidade e à infância, a assistência aos desamparados, na forma desta Constituição (BRASIL, 1988, não paginado).
} 


\section{Políticas públicas e direito à saúde: necessidade de uma alternativa para além da judicialização}

proteção das pessoas no contexto de sua situação concreta na sociedade." (SARLET, 2011, p. 131).

O direito à saúde é um dos direitos sociais fundamentais, e sobre ele se detém o presente artigo. Assim, salienta-se, inicialmente, que o conceito de saúde evoluiu, hoje não mais é considerada somente como ausência de doença. A Organização Mundial de Saúde OMS, no preâmbulo de sua Constituição de 1946 define que "A saúde é um estado de completo bem-estar físico, mental e social, e não consiste apenas na ausência de doença ou de enfermidade." (ORGANIZAÇÃO MUNDIAL DA SAÚDE, 1946, não paginado).

Esse conceito foi utilizado por muitos anos e vem sendo expandido para incorporar as dimensões física, emocional, mental, social e espiritual do homem. Atualmente, compreende-se que a saúde não é um fenômeno isolado, mas o resultado da interação de todas as condições em que vive a população, como argumenta Pereira (2014, p. 65):

Não se pode considerar o indivíduo fora de sua realidade, econômica, social e ambiental. O clima, o tipo de moradia, a qualidade da água consumida, a possibilidade dos tratamentos dos dejetos domésticos, o ar que se respira, a degradação social ou a desnutrição, estilos de vida pessoais e formas de inserção de diferentes parcelas da população no mundo do trabalho. A saúde é produto e parte do estilo de vida, das condições de existência e do equilíbrio das diversas dimensões do homem.

Sendo, então, a saúde resultante de diferentes dimensões, para se chegar ao seu melhor conceito, imprescindível observar o ser humano como um todo, suas condições de vida, de habitação, de trabalho e de acesso aos serviços de saúde. Essa é a primeira ampliação conceitual que deve ser feita, pois somente a partir desse alargamento conceitual e de conteúdo se podem pensar boas políticas públicas, direcionadas a garantir a saúde dos indivíduos, entendendo que, muitas vezes, alcançar este estado exigirá melhorar a qualidade e condições de vida da população. Isso por que:

A incorporação à base jurídico-legal do SUS de uma concepção ampliada de saúde que inclui os condicionantes econômicos, sociais, culturais e bioecológicos e uma visão abrangente e integrada das ações e serviços de saúde, busca superar a visão dominante de enfocar a saúde pela doença, sobretudo nas dimensões biológica e individual. Sem negar o peso e a importância das doenças na configuração de sistemas de saúde e na consequente oferta de ações (VASCONCELOS E PASCHE, 2012, p. 532).

No mesmo sentido, ao tratar da equidade na saúde, Sen (2000, p. 74), acrescenta:

Equidade na saúde não pode se preocupar somente com a saúde, isoladamente. (...). Equidade na saúde com certeza não se refere apenas ao acesso à saúde, muito menos ao enfoque ainda mais restrito do acesso aos serviços de saúde. Na verdade, equidade na saúde como conceito tem um alcance e uma relevância extremamente amplos.

Assim, ao pensar em saúde, deve-se pensar em um conceito que engloba a própria noção de justiça, pois qualquer teoria de justiça social que busque uma distribuição de bens e riquezas na sociedade de forma equitativa e também se preocupe em dar ao ser humano 
condições de desenvolver suas capacidades, não pode esquecer-se da importância da saúde para que o crescimento individual e social seja possível.

Por isso, em busca de uma melhor abordagem para políticas de saúde não se pode esquecer que a saúde tem de levar em conta uma série de fatores que não são apenas sociais e econômicos, "mas também uma variedade de outros parâmetros, como deficiências pessoais, predisposições individuais e doenças, riscos epistemológicos de regiões especificas, influência de variações climáticas etc.” (SEN, 2000, p. 86).

A partir do artigo $196^{6}$, o constituinte reconhece a saúde como direito de todos e dever do Estado, dando destaque a essas políticas sociais e econômicas que visem à redução do risco de doença e de outros agravos e ao acesso universal e igualitário às ações e serviços para sua promoção, proteção e recuperação. O que demonstra, de forma clara, que o constituinte relacionou, desde logo, o direito à saúde a toda a coletividade.

Porém, torna-se restritivo demais e, no mínimo errado, compreender o direito à saúde apenas sob a ótica da coletividade. Pois, por óbvio, a questão da saúde envolve, além da coletividade, o indivíduo em sua particularidade. Essa é a segunda ampliação que precisa ser feita, para partir do pressuposto de que o direito fundamental à saúde, embora previsto no rol dos direitos sociais, pode também ser tutelado na esfera individual, porque sua fruição se dá no plano do indivíduo.

O Estado deve planejar e executar políticas públicas e serviços públicos que garantam saúde das pessoas, mas deve também garantir à saúde de cada pessoa individualmente. Em outras palavras: o Estado deve assegurar saúde à coletividade, mas não pode se escusar de nenhum indivíduo, porque ao lado do interesse geral há o interesse pessoal e as pessoas vão manifestar necessidades diferentes. "Cuida-se, portanto, de direito de todos e de cada um, de tal sorte que o desafio é saber harmonizar, sem que ocorra a supressão de uma das dimensões, ambas as perspectivas." (SARLET, 2011, p. 144).

Nesse sentido, falar em direito à saúde é falar em direito a cuidados de saúde, que se materializa preferencialmente como o direito às políticas públicas. Mas, "não quer isto dizer que é um direito a aquilo que o Estado resolver prestar ou se comprometer a prestar" (AMARAL, 2011, p.98). A saúde não é apenas um direito, mas há um dever imposto pela Constituição de desenvolver tais políticas e um dever de eficiência e de cobertura universal.

Em sentido amplo, o direito à saúde abrange a consecução de medidas para salvaguarda do direito e da própria saúde dos indivíduos, bem como a organização de instituições, serviços, ações e procedimentos. Em sentido estrito, a dimensão prestacional traduz-se no fornecimento de bens materiais ao titular desse direito fundamental (SARLET; FIGUEIREDO, 2008).

Assim, é dever do Estado garantir a saúde ao cidadão mediante acesso universal e gratuito, o que implica na organização de um complexo de ações e serviços, aptos a tornar possível acesso de todos os brasileiros como potenciais usuários do Sistema Único de Saúde SUS.

O Estado não outorga saúde à população, mas cria uma estrutura que mantém um sistema público de saúde visando dar efetividade ao texto Constitucional. É nesse sentido que o SUS pode ser concebido, como o conjunto de ações e serviços de saúde, fornecido por órgãos e instituições públicas que compõe os entes federativos.

\footnotetext{
${ }^{6}$ Artigo 196 da CRFB/88. A saúde é direito de todos e dever do Estado, garantido mediante políticas sociais e econômicas que visem à redução do risco de doença e de outros agravos e ao acesso universal e igualitário às ações e serviços para sua promoção, proteção e recuperação (BRASIL, 1988, não paginado).
} 
A CRFB/88 e a Lei Orgânica da Saúde (LOS) - Lei no 8.080/90, trazem um rol de princípios, objetivos e garantias, que representam as bases do planejamento do SUS e servem de orientação para a estratégia de atuação da Administração Pública.

Sobre isso, Prata (2013, p. 254) sintetiza:

Os princípios do sistema de proteção à saúde, instituídos pelo art. 196 da Constituição e art. $2^{\circ}, \S 1^{\circ}$, da LOS são a universalidade, a igualdade e a gratuidade no acesso ao sistema do SUS.

$\mathrm{O}$ principio da universalidade tem por objetivo os titulares do direito à saúde, outorgando a garantia de que toda e qualquer pessoa, no território brasileiro, possa ter acesso gratuito aos serviços de saúde oferecidos pela rede pública de atendimento.(...)

O princípio da igualdade garante aos usuários do sistema as mesmas oportunidades de acesso aos serviços de saúde, sem distinções, preconceitos ou privilégios.

(...)

O princípio da integralidade, por sua vez, é previsto no inciso II do art. 198 da Constituição e fixa como uma das diretrizes do sistema de saúde pública a totalidade de abrangência de atendimento, em todos os níveis de complexidade, sintetizando desta forma os princípios da universalidade e igualdade.

Desse modo, o direito à saúde exige da Administração Pública efetividade de suas políticas públicas, requer esta interpretação ampliativa, de modo a observar todas as realidades que envolvem o indivíduo e a não excluir ninguém, força atuação proativa e pautada em princípios de boa administração, pois só assim todas as metas do SUS serão alcançadas. É que as políticas públicas de saúde vinculam a atividade estatal.

O conteúdo jurídico dos direitos sociais, especialmente do direito à saúde, não pode ser esvaziado em nenhum sentido, nem mesmo pelo fato de já existirem políticas públicas e ainda que elas fossem eficazes, o que não tem acontecido na realidade prática brasileira, razão pela qual, nesses casos de falhas ou desvios, ou seja, na configuração de uma lesão a esse direito, que a apreciação judicial não pode ser excluída. Sobre essa questão, passa-se a detalhar na próxima seção.

\section{POLÍTICAS PÚBLICAS COMO INSTRUMENTO PARA EFETIVAÇÃO DO DIREITO À SAÚDE: O EXCESSO DE JUDICIALIZAÇÃO}

Política pública é um elemento ainda novo na seara jurídica, mas o seu estudo demonstra total relevância como instrumento para que o direito deixe de figurar apenas no plano formal para tornar concreto o conteúdo das normas jurídicas aos cidadãos. Essa é uma característica indispensável para o Estado Social, gestado no século XIX, no qual se funda a República Federativa do Brasil, que traz consigo um novo conceito de cidadania aflorado no século XX.

Igualmente a partir do século XIX toma força a corrente econômica vigente até os dias atuais, na afirmação da necessidade de intervenção do Estado na economia, de modo a atenuar as desigualdades econômicas, os contrastes sociais e melhorar o bem estar das pessoas. A teoria do Estado Social se caracteriza por esta atuação estatal na garantia do 
mínimo necessário às pessoas, garantia de direitos e adoção de políticas públicas com efeitos redistributivos (SMANIO, 2015, p.2).

Assim, as políticas públicas são arranjos complexos, típicos da atividade políticoadministrativa. Referem-se a institutos diversos com incidências em várias áreas do conhecimento e atuação humana, por isso também o direito deve conhecer e descrever, pois elas norteiam toda a atividade do Estado para consecução de direitos das pessoas.

Estes arranjos estão diretamente ligados aos fundamentos da República elencados na Constituição cidadã de 1988, especialmente de cidadania e dignidade da pessoa humana, como citado na segundo seção. Portanto, as políticas públicas devem ser entendidas como categorias jurídicas normativas, assim como os princípios jurídicos e as regras jurídicas.

Por isso, importante destacar o conceito de Dworkin (2002, p. 37) de políticas públicas:

Denomino "política" aquele tipo de padrão que estabelece um objetivo a ser alcançado, em geral uma melhoria em algum aspecto econômico, político ou social da comunidade (ainda que certos objetivos sejam negativos pelo fato de estipularem que algum estado atual deva ser protegido contra mudanças adversas).

Esse conceito traz em si uma importância fundamental, pois, segundo destaca Smanio (2013, p. 5), “(...) ainda nos EUA, coube a Ronald Dworkin, no final da década de 1970, o entendimento de que o tema Políticas Públicas também deveria caber na Teoria Geral do Direito".

De mais a mais, não restam dúvidas do interesse jurídico deste conceito, dado o caráter do nosso Estado Social e a imposição da nossa Constituição. A realidade social, atualmente, impõe ao Estado uma grande gama de atividades em prol da garantia da cidadania e efetivação de direitos sociais fundamentais, aqui entendidos como um mínimo indispensável para uma vida digna. "O Estado Social legitima-se, antes de tudo, pela realização de políticas, isto é, programas de ação" (GRAU, 2005, p. 26).

Ainda sobre a conceituação de políticas públicas, destaca-se o conceito que melhor resume todos os que foram citados. Bucci (2006, p. 39) assevera que são:

Programas de ação governamental que resulta de um processo ou conjunto de processos juridicamente regulados - processo eleitoral, processo de planejamento, processo de governo, processo orçamentário, processo legislativo, processo administrativo, processo judicial - visando coordenar os meios à disposição do Estado e as atividades privadas, para a realização de objetivos socialmente relevantes e politicamente determinados.

Desse modo, as políticas públicas sociais, de responsabilidade, especialmente, dos Poderes Legislativo e Executivo, são a via primeira de materialização dos direitos sociais fundamentais e normas constitucionais definidoras de tais direitos e são, ainda, mais do que simples programas de governo, uma vez que se caracterizam como verdadeiras normas jurídicas, dotadas, assim, de imperatividade.

Nesse sentido, "não há como não fixarmos um conceito jurídico de políticas públicas, pois estas são também fenômeno jurídico, que pode ser realizado, executado, controlado, enfim efetivado juridicamente" (SMANIO, 2013, p. 10).

E ainda: 


\section{Políticas públicas e direito à saúde: necessidade de uma alternativa para além da judicialização}

O Estado assume a tarefa de proporcionar prestações necessárias e serviços públicos adequados para o pleno desenvolvimento da personalidade humana, por meio da realização de fins materiais. Para cumprir os ideais de Estado Social, a ação dos governantes deve ser racional e planejada, o que ocorre por meio da elaboração e implementação de políticas públicas.

As políticas públicas, definidas como programas de ação governamental voltados à concretização dos direitos fundamentais, (...) (DUARTE, 2013, p. 16-17).

O Estado deve ter atuação decisiva na formulação das políticas públicas voltadas para realização de direitos fundamentais, especialmente o direito à saúde, diminuição de desigualdade na aquisição de serviços públicos a partir do planejamento, com a utilização de instrumentos de participação social, fomentando o debate sobre os assuntos relevantes para a população. E, após isso, deve atuar na execução dessas medidas com vistas à eficiência e adequação, além de trabalhar sempre com a transparência de modo que os cidadãos possam controlar o alcance dos objetivos e metas almejados.

Contudo, na prática, há eventuais falhas na prestação do direito à saúde pelo Estado que não podem ser desconsideradas pelo Poder Judiciário quando provocado pelos indivíduos. É o que se chama de judicialização do direito à saúde, "significa que questões relevantes do ponto de vista político, social ou moral estão sendo decididas, em caráter final, pelo poder judiciário" (BARROSO, 2012, p. 05).

Esse fenômeno impõe aos juízes e tribunais a decisão em demandas que envolvem políticas públicas de responsabilidade do Executivo e que, a depender da análise do caso concreto, não estão atendendo o ideal do legislador e assim, sonegando ao cidadão o seu direito de viver, às vezes de sobreviver. Nesse sentido, a judicialização pode ser vista como:

A judicialização das políticas públicas acontece, via de regra, na concretização de direitos fundamentais e não deve ser vista como uma intromissão anômala de um poder sobre o outro. Não se trata de uma disfunção em face do principio da separação dos poderes, mas corrobora a regra do check and balance, pela qual existe a saudável possibilidade de cada poder estatal interferir no outro, para controle e alinhamento das respectivas atuações, em busca da melhor concretização do projeto de país e sociedade que foi desenhado na carta institucional. (CASTRO; VALLE; ANSCHAU; FERREIRA, 2012, p. 22-23).

Portando, diante de uma lesão ao direito à saúde o judiciário é legitimo para intervir, tanto em demandas coletivas quanto individuais, e o progressivo aumento dessas demandas envolvendo esse direito fundamental é um indicativo de falha na prestação de serviços de saúde e garantia pelo Estado, o que não pode ser aceito e não se justifica diante das características de imperatividade das normas, como foi visto até aqui.

Por outro lado, para muitos autores, pensar desse modo, irrestritamente, não se mostra a melhor solução para os problemas de saúde, ou da ausência de tratamentos de saúde no Brasil. Isso porque, segundo Amaral (2011, p. 95):

O resultado desta visão tem sido tornar o Judiciário o alocador de recursos públicos no campo de remédios, tornar a compra emergencial e sem licitação rotina e, ao final, não haver um critério de mediação dos resultados. Será que mais vidas foram salvas com o provimento judicial sendo critério majoritário 
de alocação de recursos na saúde? Ou será que o "custo" medido em vidas dos "financiadores ocultos" das decisões alocativas tomadas nas lides, aqueles que deixam de receber o órgão, deixaram de ter acesso à política pública que seria desenvolvida com a verba realocada é mais elevado que o benefício?

Estas são questões que precisam ser enfrentadas, pois o judiciário "não pode ser permanentemente canal de reivindicação e, quando isso acontece, é sinal claro de que outros canais estão obstruídos (...)" (SANSON, 2013, p. 125). E ainda, - embora sabido que esta não é a realidade do Brasil, uma vez que as políticas públicas aqui implementadas não são eficientes, mas à guisa de argumentação, - de nada adiantaria um cenário extremamente favorável de políticas bem estruturadas somente em uma determinada área, se há outras ameaças à vida e à saúde que não são combatidas, tais como a violência urbana, estrutura hospitalares, saneamento básico, dentre outras ameaças que também precisam ser reparadas.

E mais, as características do direito à saúde não estão acabadas, trata-se de um direito que não tem uma definição final, antes exige um exame atencioso das situações do caso concreto, pois, como dito no tópico anterior, trata-se de um conceito amplo. Assim, o deslocamento irrestrito da decisão para o judiciário, embora possível e legítima, tem seus riscos, o judiciário está preparado para fazer escolhas, mas nem sempre é ideal que as faça.

O presente trabalho em nenhum momento pretende defender limites à atuação do Judiciário, ao contrário, acredita-se que sempre que provocado o Judiciário é legítimo para agir e deve, sempre no sentido de garantir direito à saúde a todo àquele que dela necessite. $\mathrm{O}$ que se está a dizer é que não deveria ser assim, ou seja, tratando-se de um direito fundamental e constitucionalmente garantido, dotado de imperatividade para sujeitar a atuação dos Poderes Públicos à sua garantia, deveriam esses Poderes concretizar o mandamento do Constituinte e garantir, antes de especificamente direitos fundamentais sociais, garantir a própria dignidade da pessoa humana, que, em ultima análise se mostra o fundamento dos direitos sociais.

Assim, tratar do assunto da judicialização é adentrar em um campo delicado. Ao juiz é feita uma alta exigência. Estará nas mãos dele a interpretação de diversos dispositivos legais e caberá a ele encontrar um sentido decorrente dessa interação de valores, desta mistura de conteúdos, sempre fazendo a melhor ponderação, pois "(...) as numerosas normas de um sistema jurídico desenvolvido deveriam "fazer sentido" quando consideradas em conjunto" (MACCORMICK, 2006, p. 197) ${ }^{7}$.

$\mathrm{O}$ assunto é tão relevante que, a partir da Audiência Pública $\mathrm{n}^{\circ} 4$, realizada pelo Supremo Tribunal Federal (STF), em maio e abril de 2009, na qual foram discutidas questões relativas às demandas judiciais relacionadas à assistência à saúde, quando foram ouvidos 50 (cinquenta) especialistas na matéria, considerando o número de ações judiciais sobre o tema e a consequente necessidade de aprofundar estudos com vistas à prevenção de litígios e à adequada gestão dos processos em tramitação, o Conselho Nacional de Justiça (CNJ), constituiu um grupo de trabalho (Portaria n. 650, de 20 de novembro de 2009).

Os trabalhos do grupo culminaram na aprovação da Recomendação n. 31, de março de 2010, pelo Plenário do Conselho Nacional de Justiça (CNJ), que especifica diretrizes de julgamento aos magistrados em demandas judiciais que envolvem a assistência à saúde. Em abril de 2010, o CNJ criou, por meio da resolução n. 107, o Fórum Nacional do Judiciário para monitoramento e resolução das demandas de assistência à Saúde - Fórum da Saúde. E,

\footnotetext{
7 Sobre argumentação jurídica e atividade de decisão judicial sugere-se a obra: MACCORMICK, Neil. Argumentação jurídica e teoria do direito. Trad. Waldéa Barcellos. 1 ed. São Paulo: Martins Fontes, 2006. 


\title{
Políticas públicas e direito à saúde: necessidade de uma alternativa para além da judicialização
}

para subsidiar com informações estatísticas os trabalhos do Fórum foi instituído um sistema eletrônico de acompanhamento das ações judiciais que envolvem a assistência à saúde.

Em 2016, O CNJ editou Resolução n ${ }^{\circ}$ 238/2016, que versa sobre a criação e manutenção dos Comitês Estaduais de Saúde, no âmbito dos Tribunais de Justiça Regionais Federais, com objetivo de fortalecer o trabalho conjunto com o Poder Judiciário para uma adequada concretização das políticas públicas voltadas à saúde, fomentando o diálogo e a participação de interessados, sem, contudo pretender que os Comitês funcionem como instância de correção de gestões inadequadas dos administradores.

Há ainda, outras propostas, fomentadas pelo CNJ, no âmbito dos tribunais, segundo relata Prata (2013, p. 265):

\begin{abstract}
Outra proposta é a instituição de núcleos de assistência às demandas judiciais compostos por equipes multidisciplinares. O CNJ pretende incentivar os convênios entre os Tribunais de Justiça e as Secretarias de Saúde dos Estados para formação destes núcleos, com embasamento na experiência bem-sucedida do Núcleo de Assessoria Técnica (NAT), no Estado do Rio de Janeiro. Nesse sistema, permite-se ao NAT acesso imediato à listagem de medicamentos disponíveis em estoque da Secretaria de Saúde, viabilizando a agilização do fornecimento e a efetividade da medida.
\end{abstract}

No TJBA foi adotado o regime de plantão 24 horas para ações judiciais na área de saúde, também com pareceres prévios emitidos por equipe multidisciplinar para dar amparo à decisão judicial, possibilitando o acesso À decisão judicial de forma mais rápida. (...)

Ações desse tipo são, todas, louváveis, mas demonstram que há, no Brasil, não só uma crise nos Poderes Executivo e Legislativo, como também uma crise no sistema público de saúde, que expõe milhares de pessoas a condições de péssimo atendimento, quando não a ausência dele. Por isso, entende-se que o estudo das Políticas Públicas não pode estar limitado às condições de exigibilidade judicial desta categoria, uma vez que para compreender esse fenômeno é preciso investigar a lógica que está por trás desse complexo processo de tomada de decisão. Os problemas que surgem estão relacionados à falta de planejamento, organização e execução administrativa.

O foco de observação devem ser os fatores determinantes que deveriam guiar os processos de tomada de decisão, coisas que ocorrem antes da judicialização. Isso porque o excesso de judicialização não é capaz de resolver o problema da efetivação dos direitos que dependem, pelo menos a priori, para sua concretização, da elaboração de políticas públicas.

Diante de tudo isso, torna-se de evidente importância repensar a judicialização como forma de concessão de direitos sociais fundamentais, especialmente o direito à saúde, vê-se que as necessidades urgentes do Brasil, são de alternativas que sejam para além, anteriores a judicialização, de modo a garantir direitos sociais sem que seja necessária a tutela judicial e da melhor forma possível. É o que se propõe nestas breves linhas.

\section{PARA ALÉM DA JUDICIALIZAÇÃO}

Entendido, primeiramente, o conteúdo do direito à saúde, o tratamento dado pelo legislador a esse direito no rol dos direitos sociais fundamentais e a forma de atuação que a 
CRFB/88 impôs ao Estado para sua garantia. Depois, apresentada conclusão de que a judicialização não é a forma ideal para concretização do direito à saúde, resta pensar em alternativas que estejam para além das demandas judiciais, de modo a evitá-las.

Retomando o conceito de políticas públicas de Bucci (2006, p. 39), utilizado na seção três e que foi considerado ser o melhor para os objetivos deste artigo, um dos elementos essenciais é, exatamente, a ação do Estado. A política pública denota um dever do Estado que assume para si a obrigação de realizar um projeto político de sociedade que foi desenhado na CRFB/88. Não se trata de uma ação qualquer, mas ação que busca a realização de uma meta preestabelecida pelo legislador em um moderno Estado Social.

Portanto, a atuação do Estado deve sempre levar em conta a concretização de um projeto de sociedade "pautado na redução de desigualdades e na promoção do desenvolvimento. Esse projeto de nação, entre nós, está sintetizado no art. $3^{\circ}$ da $\mathrm{CF} / 88^{\text {" }}$ (DUARTE, 2015, p. 14).

O Estado é o grande agente do desenvolvimento e, para isso, deve articular os meios disponíveis para alcançar o fim constitucionalmente estabelecido. Isso "imprime um tipo de racionalidade necessária à sua [atuação do Estado] atuação: aquela baseada no planejamento (cf. art. 174 da CF/88)" (DUARTE, 2015, p. 13). Logo, a escolha dos instrumentos pode variar, os programas de ação podem ser diferentes, mas o objetivo a ser alcançado está determinado.

Nesse contexto, a atuação de outros atores também desponta, como o Ministério Público (MP), que deve buscar, nos limites de sua atuação, os objetivos elencados no artigo $3^{\circ}$ da CRFB/88. O MP deve definir sua própria política institucional com base no Estado Social e Democrático de Direito, pode incluir na sua agenda ações de diálogo entre instituições e criação de grupos de trabalho específicos, para então, após estabelecidas essas metas, interferir na agenda de outros órgãos e Poderes, caso determinada política pública não esteja de acordo com os parâmetros constitucionais.

Sobre esta atuação do MP, Duarte (2015, p. 15) esclarece que:

Na realidade, muitos setores do MP têm se destacado na busca de soluções extrajudiciais de conflito de natureza coletiva ou difusa, numa atuação mais resolutiva. Baseada na busca de uma solução direta, com a participação dos interessados, indo ao judiciário de maneira excepcional.

O que se vê é que as garantias processuais - remédios jurídicos usados perante os tribunais - embora importantes, não são capazes de satisfazer adequadamente direitos fundamentais que devem ser concretizados por meio de politicas públicas. O Judiciário pode intervir, mas pensar em política pública é pensar em conjunto de ações dos Poderes e órgãos públicos com objetivo de atender uma demanda. Logo, a solução envolve recurso, planejamento orçamentário, coordenação de ação em diferentes esferas do poder, ou seja, não se pode prescindir de medidas como a criação de leis e órgãos, o que se dá pela atuação do Legislativo. Se assim não for, a resolução de uma demanda individual não resolverá o problema maior, que está na política pública, e a mesa dos juízes continuará cheia de processos onde os efeitos das decisões se restringem a lide.

Em suma, é preciso perceber que a concessão de um medicamento ou de um leito em um caso específico, embora medida necessária no caso concreto, não resolve o problema da saúde pública. Outras pessoas continuarão à margem desses direito, sendo ele privilégio daqueles que possuem advogado, conhecem o trabalho da defensoria, sabem dos seus direitos, se lançam em uma demanda judicial, quando outros, desconhecidos e desinformados, continuam a padecer com seus males. 


\section{Políticas públicas e direito à saúde: necessidade de uma alternativa para além da judicialização}

Sobre esse aspecto, ressalta Amaral (2011, p. 111) que "parece adequado esperar que o Supremo Tribunal Federal e o Superior Tribunal de Justiça busquem proferir decisões que transcendam a adjudicação para apenas o caso entre as partes diretamente envolvidas". E ainda, em relação a estas demandas individuais, acrescenta que:

(...). Se o Judiciário, ao invés de substituir a decisão do agende político pela sua, exigir deste que num prazo curto justifique suas escolhas e procedimentos e, ao final desse prazo, apreciar as razões trazidas, ainda que para não acatá-las, talvez se esteja dando um grande passo para uma maior racionalização (AMARAL, 2011, p. 112).

Outro ponto de singular importância é a participação social no processo de tomada de decisão em um Estado Democrático de Direito. A CRFB/88 garante voz ao cidadão e esta não pode deixar de ser ouvida. Ao contrário, o cidadão deve ser estimulado a participar do diálogo interinstitucional de elaboração das políticas públicas e fisscalização da atuação estatal. "Este é um elemento essencial das políticas públicas: a abertura à participação dos interessados." (DUARTE, 2015, p. 17).

Desse modo, quando se trata de um direito tão essencial para todos, é preciso que algumas decisões sejam tomadas de forma coletiva. É fundamental que haja uma maior democratização do processo que envolve as politicas públicas, o que leva a uma maior legitimação, fiscalização e transparência.

Nesse sentido, assevera Smanio (2013, p. 10) que as políticas públicas "pressupõem as relações do Estado com a sociedade, pois que a via da participação dos cidadãos deve ser o método a ser buscado, tanto para sua formulação, quando para sua execução" e, acrescenta posteriormente que "a qualidade da democracia implica na qualidade das Políticas Públicas efetivadas e, portanto, na garantia dos Direitos Fundamentais e da Cidadania" (SMANIO, 2013, p. 11).

Essa participação consolida uma cooperação entre o Estado e a sociedade, assim como entre os próprios cidadãos, criando um vínculo maior de legitimidade para as políticas públicas, o que favorece uma maior certeza de que o Estado está atuando com transparência e com vistas ao bem comum. É preciso, portanto, fortalecer o ciclo das políticas públicas e fomentar a participação de todos os atores envolvidos, sempre numa abordagem multidisciplinar, o que inclui profissionais do direito, da gestão pública, dos Poderes da União, da saúde, e demais atores.

Por isso, fundamental reiterar a afirmação de Ribeiro (2013, p. 44):

O principal desafio na implementação das políticas públicas e na efetivação dos direitos sociais contidos na Constituição de 1988 não é econômico, mas político, em dois sentidos. Em primeiro lugar, o enfrentamento do modelo econômico que se baseia na hegemonia neoliberal e, em segundo lugar, aumentar a participação cidadã na elaboração, execução e fiscalização dessas políticas através da ampliação dos espaços de participação política e da esfera pública democrática via sociedade civil organizada.

Quando se fala de desafios políticos se quer destacar que há a necessidade de que o processo político seja revisto, aquele que se dá no âmbito do Executivo e do Legislativo. Os meios econômicos algumas vezes se mostram escassos, o que é uma falácia, pois eles podem ser readequados, repensados, realocados, de acordo com o que é essencial e, este processo é 
essencialmente político e deve ser enfrentado na fase de elaboração das políticas públicas, uma vez que não é de responsabilidade constitucional do Judiciário a elaboração das propostas orçamentárias.

Quando o enfrentamento dessa questão não acontece no momento correto e no âmbito de discursão adequado, a consequência é extremamente danosa, pois ai que o número de demandas judiciais cresce e os efeitos da judicialização pode piorar a situação do orçamento.

O resultado da transferência do debate que deve ser público para o judiciário é, nas palavras de Barroso (2012, p. 13):

(...) uma dose excessiva de politização dos tribunais, dando lugar a paixões em um ambiente que deve ser presidido pela razão. No movimento seguinte, processos passam a tramitar nas manchetes de jornais - e não na imprensa oficial - e juízes trocam a racionalidade plácida da argumentação jurídica por embates próprios da discussão parlamentar, movida por visões políticas contrapostas e concorrentes.

Assim, a crítica que se faz, atualmente, a judicialização é a crítica ao próprio Estado Brasileiro, sua forma de atuação, suas instituições e administradores públicos, uma crítica que se estende a atuação do próprio cidadão. Ou seja, é preciso que se caminhe rumo a uma mudança estrutural. É difícil, mas não se pode perder a esperança.

\section{CONSIDERAÇÕES FINAIS}

Em sede de conclusão, destaca-se que a saúde é um direito, portanto, deve ser reconhecido pelo Estado constitucional. É social, o que significa que deve se tornar concreto por meio de políticas públicas voltadas à coletividade, a despeito de ter sua fruição no plano individual, além do que envolve uma gama de elementos que circunscrevem a pessoa humana, o que requer uma ampliação conceitual na elaboração de planos de ação para sua garantia e efetivação.

Por fim - não hierarquicamente - é fundamental, ou seja, indispensável para a vida, um direito que compreende um conjunto básico que deve ser assegurado a todos como imperativo de cidadania e dignidade.

Por outro lado, a quantidade crescente de demandas judiciais envolvendo direito à saúde demonstra a fragilidade das políticas públicas para garantia desse direito, o que é inaceitável. Mas, ao mesmo tempo em que legítima a possibilidade de recorrer ao Judiciário, não se mostra o meio mais adequado para resolver o problema macro da saúde, exatamente porque a má gestão dessas políticas se mostra o real problema enfrentado pela sociedade.

A atuação do judiciário é importante e pode ser de grande serventia, o desafio do diagnostico das ações envolvendo direito à saúde, a atuação do $\mathrm{CNJ}$ e dos tribunais representa novas formulas de políticas públicas que devem ser observadas pela Administração e servem de exigência de uma maior eficiência do Estado no gerenciamento do SUS, tudo com vistas também a diminuir o número de demandas judiciais.

Porém, diante de todo esse contexto, urgente que se busque alternativas para o alcance de bons e eficientes serviços de saúde, ao cargo, inicialmente do Executivo e do Legislativo, evitando que o individuo precise recorrer ao Judiciário. 
Acredita-se que isso se dará no fortalecimento das políticas públicas, no maior diálogo institucional e fomento da participação social, os indicativos do judiciário precisam ter efeito erga omnes e não apenas inter partes.

O importante, no que diz respeito às políticas públicas de saúde, tão essenciais para as pessoas, é que haja um estudo em conjunto e com responsabilidade de todos os atores envolvidos, de modo a ser observado os aspectos levantados no presente texto, como a ampliação conceitual já destacada, observância as questões de orçamento e como melhor alocar os recursos, a Lei de Responsabilidade Fiscal, elaborando políticas com critérios de transparência, diálogo e participação, porque só assim se poderá tornar concreta a exigência Constitucional.

\section{REFERÊNCIAS}

AMARAL, Gustavo. Saúde direito de todos, saúde direito de cada um: reflexões para a transição da práxis judiciária. In: NOBRE, Milton Augusto de Brito; SILVA, Ricardo Augusto Dias da (Coord.). O CNJ e os desafios da efetivação do direito à saúde. Belo Horizonte: Fórum, 2011. p. 81-115.

BARROSO, Luis Roberto. Constituição, democracia e supremacia judicial: direito e política no Brasil contemporâneo. Revista da Faculdade de Direito da UERJ, Rio de Janeiro, v. 2, n. 21, jan./jun. 2012. Disponível em: $<\quad$ http://www.epublicacoes.uerj.br/index.php/rfduerj/article/view/1794/2297> Acesso em: 15 ago. 2016.

BRASIL. Constituição da República Federativa do Brasil de 1988. Disponível em: <http://www.planalto.gov.br/ccivil 03/constituicao/constituicao.htm>. Acesso em: 12 abr. 2016.

BRITO FILHO, José Claudio Monteiro de. Direitos fundamentais sociais: realização e atuação do Poder Judiciário. Revista do TRT da $8^{\text {a }}$ Região, Belém, v. 41, n. 81, p. 77-87, jul./dez. 2008. Suplemento Especial Comemorativo.

BUCCI, Maria Paula Dallari. O conceito de política pública em direito. In: BUCCI, Maria Paula Dallari (Org.). Políticas públicas - reflexões sobre o conceito jurídico. São Paulo: Saraiva, 2006.

CASTRO, Flavia de Almeida Viveiros de; VALLE, Caroline; ANSCHAU, Lorena Coser Doano; FERREIRA, Marcela Bravo. Análise do impacto das decisões judiciais sobre o orçamento da União no caso da saúde pública: Possibilidade e contingenciamento dos riscos.

Revista Tributária e de Finanças Públicas, ano 20, volume 102, p. 15-40, 2012.

DIAS, Jean Carlos. O controle judicial de políticas públicas. São Paulo: Método, 2007.

DUARTE, Clarisse Seixas. O ciclo das políticas públicas. In: SMANIO, Gianpaolo Poggio. BERTOLIN, Patrícia Tuma Martins. O Direito e as Políticas Públicas no Brasil. São Paulo: Atlas, 2013, p. 16-43 (capítulo 2). 
Para além da Judicialização: a necessidade de uma nova forma de abordagem das Políticas Públicas. In: SMANIO, Gianpaolo Poggio; BERTOLIN, Patrícia Tuma Martins; BRASIL, Patricia Cristina. O Direito na Fronteira das Políticas Públicas. São Paulo: Páginas \& Letras Editora e Gráfica, 2015, p. 13-18.

DWORKIN. Ronald. Levando os direitos à sério. Trad. Nelson Boeira. 1 ed. São Paulo: WMF Martins Fontes, 2002.

GRAU, Eros Roberto. O direito posto e o direito pressuposto. São Paulo: Malheiros, 2005. p.26.

MACCORMICK, Neil. Argumentação jurídica e teoria do direito. Trad. Waldéa Barcellos. 1 ed. São Paulo: Martins Fontes, 2006.

ORGANIZAÇÃO MUNDIAL DA SAÚDE. Constituição da Organização Mundial da Saúde (OMS/WHO). Nova Iorque, 1946. Disponível em: $<$ http://www.direitoshumanos.usp.br/index.php/OMS-Organiza\%C3\%A7\%C3\%A3oMundial-da-Sa\%C3\%BAde/constituicao-da-organizacao-mundial-da-saude-omswho.html> Acesso em: 5 jun. 2016.

PEREIRA, Leonardo Fadul. Igualdade formal e segurança jurídica nas decisões judiciais em ações coletivas para fornecimento de medicamentos: um estudo de casos da seção judiciária federal do estado do pará. Belém, dissertação de mestrado, Programa de PósGraduação em Direito, Políticas Públicas e Desenvolvimento Regional do Centro Universitário do Pará - CESUPA, 2014.

PRATA, Lucília Alcione. Um Novo Locus de Formação das Políticas Públicas de Saúde: o Diagnóstico da Saúde pela Política Judiciária do Conselho Nacional de Justiça. In: SMANIO, Gianpaolo Poggio. BERTOLIN, Patrícia Tuma Martins. O Direito e as Políticas Públicas no Brasil. São Paulo: Atlas, 2013, p. 45-62 (capítulo 3).

RIBEIRO, Hélcio. Constituição, Participação e Políticas Públicas. In: SMANIO, Gianpaolo Poggio. BERTOLIN, Patrícia Tuma Martins. O Direito e as Políticas Públicas no Brasil. São Paulo: Atlas, 2013, p. 248- 270.

SARLET, Ingo Wolfgang; FIGUEIREDO, Mariana Filchtiner. Algumas considerações sobre o direito fundamental à proteção e promoção da saúde aos 20 anos da Constituição Federal de 1988. Revista de Direito do Consumidor. São Paulo, n. 67, p. 125-172, 2008.

SARLET, Ingo Wolfgang. Algumas considerações em torno do conteúdo, eficácia e efetividade do Direito à saúde na Constituição de 1988. Revista Eletrônica da Reforma do Estado, Salvador, n. 11, set./nov. 2007. Disponível em:<http://www.direitodoestado.com.br/rere/edicao/11> Acesso em: 15 jan. 2015.

A titularidade simultaneamente individual e transindividual dos direitos sociais analisada à luz do exemplo do direito à proteção e promoção da saúde. In: NOBRE, Milton Augusto de Brito; SILVA, Ricardo Augusto Dias da (Coord.). O CNJ e os desafios da efetivação do direito à saúde. Belo Horizonte: Fórum, 2011. p. 117-147. 
- Dignidade da pessoa humana e direitos fundamentais na

Constituição Federal de 1988. 9.ed., ver. atual. Porto Alegre: Livraria do Advogado, 2012.

A eficácia dos direitos fundamentais: uma teoria geral dos direitos fundamentais na perspectiva constitucional. 12 ed. rev. atual e amp. Porto Alegre: Livraria do Advogado, 2015.

SANSON, Alexandre. Os grupos de Pressão e a Consecução de Políticas Públicas. In: SMANIO, Gianpaolo Poggio. BERTOLIN, Patrícia Tuma Martins. O Direito e as Políticas Públicas no Brasil. São Paulo: Atlas, 2013, p. 118-138 (capítulo 7).

SEN, Amartya. Desenvolvimento como liberdade. São Paulo: Companhia das Letras, 2000.

SMANIO, Gianpaolo Poggio. Legitimidade Jurídica das Políticas Públicas: A Efetivação da Cidadania. In: SMANIO, Gianpaolo Poggio. BERTOLIN, Patrícia Tuma Martins. O Direito e as Políticas Públicas no Brasil. São Paulo: Atlas, 2013, p. 3-15 (capítulo 1).

Cidadania e Políticas Públicas. In: SMANIO, Gianpaolo Poggio; BERTOLIN, Patrícia Tuma Martins; BRASIL, Patricia Cristina. O Direito na Fronteira das Políticas Públicas. São Paulo: Páginas \& Letras Editora e Gráfica, 2015, p. 15 .

VASCONCELOS, Cipriano Maria de; PASCHE, Dário Frederico. O sistema único de saúde. In: CAMPOS, Gastão Wagner de Souza; MINAYO, Maria Cecília de Souza; AKERMAN, Marco; JÚNIOR, Marcos Drumond; CARVALHO, Yara Maria de (Org.). Tratado de Saúde Coletiva. 2 ed. São Paulo: Hicitec, 2012. 